This item was submitted to Loughborough's Research Repository by the author.

Items in Figshare are protected by copyright, with all rights reserved, unless otherwise indicated.

\title{
Energy loss and emissions of engine compression rings with cylinder deactivation
}

\section{PLEASE CITE THE PUBLISHED VERSION}

https://doi.org/10.1177/0954407020982868

\section{PUBLISHER}

SAGE Publications

VERSION

VoR (Version of Record)

\section{PUBLISHER STATEMENT}

This is an Open Access Article. It is published by SAGE under the Creative Commons Attribution 4.0 International Licence (CC BY 4.0). Full details of this licence are available at: https://creativecommons.org/licenses/by/4.0/

\section{LICENCE}

CC BY 4.0

\section{REPOSITORY RECORD}

Turnbull, Rob, Nader Dolatabadi, Ramin Rahmani, and Homer Rahnejat. 2021. "Energy Loss and Emissions of Engine Compression Rings with Cylinder Deactivation”. Loughborough University. https://hdl.handle.net/2134/13603244.v1. 


\section{Energy loss and emissions of engine compression rings with cylinder deactivation}

Proc IMechE Part D:

$\int$ Automobile Engineering

202I, Vol. 235(7) 1930-1943

(c) IMechE 2020

(c) (i)

Article reuse guidelines:

sagepub.com/journals-permissions DOI: 10.1 I 77/0954407020982868 journals.sagepub.com/home/pid @SAGE

\author{
Robert Turnbull' $(1)$, Nader Dolatabadi' ${ }^{(D,}$, Ramin Rahmani' ${ }^{(D)}$ and \\ Homer Rahnejat ${ }^{2}$
}

\begin{abstract}
A novel integrated multi-physics assessment of the piston top compression ring of an internal combustion engine under normal operation mode, as well as subjected to cylinder deactivation is carried out. The methodology comprises ringliner thermo-mixed hydrodynamics, elastodynamics of ring, as well as combustion gas blow-by and emissions. Therefore, the analysis provides prediction of ring-liner contact's energy losses and gas power leakage across the piston and ring crevices, as well as the resulting emissions. Cylinder deactivation (CDA) technology reduces the unburnt fuel entering the ring-pack crevices, as well as the emissions. It is also shown that the frictional and gas leakage power losses are exacerbated under CDA by as much as $20 \%$. Although this is much lower than the potential gains in fuel usage when using CDA. The optimisation of the piston compression ring would provide further fuel efficiency and improved emissions, an issue which has not hitherto received the attention which it deserves. The in-depth analysis has also shown that CDA reduces the predicted $\mathrm{CO}, \mathrm{NOx}$ and $\mathrm{HC}$ emissions by nearly as much as $8.5 \%, 10 \%$ and $8.7 \%$, respectively.
\end{abstract}

\title{
Keywords
}

Elastodynamics of piston ring, energy losses, gas blow-by, cylinder deactivation, emissions

Date received: 13 August 2020; accepted: 16 November 2020

\section{Introduction}

Two desired requirements of modern internal combustion engines (ICE) are improved energy efficiency and reduced environmental pollution. These requirements are partly driven by the ever-stringent emission legislations, ${ }^{1,2}$ and partly sought to mitigate the dwindling reserves of fossil fuels ${ }^{3,4}$ as the transport sector aims for a sustainable future. ${ }^{5}$ With $94 \%$ of the total energy demand for transport still provided by hydrocarbons, ${ }^{6}$ countering all sources of energy loss from powertrain systems ${ }^{7}$ has become critical in realising the aforementioned objectives. Richardson ${ }^{8}$ provided a breakdown of ICE losses, showing that approximately $50 \%-60 \%$ of these are related to thermal inefficiency and $15 \%$ $20 \%$ result from parasitic frictional losses.

New engine technologies such as stop-start, cylinder deactivation, indicated gear shifting strategy and variable valve actuation are aimed at improving fuel consumption of the ICEs. Cylinder deactivation is a widely adopted energy saving technology, where some cylinders are deactivated when full engine power is not required, such as in congested traffic or in steady state highway cruising. In this manner significant energy savings and reduced emissions are achieved. ${ }^{9-12}$

The primary function of the top compression rings in engine cylinders is to tightly seal the piston and the cylinder wall, mitigating gas pressure leakage. Consequently, the requirement for a tight seal can in turn lead to increased friction. This results in significant contribution to engine parasitic losses, especially from such small components as the compression rings. Therefore, effective sealing to guard against gas pressure loss can paradoxically result in increased frictional losses. At the same time owing to its thinness and structural flexibility the compression ring is also subject to elastodynamic behaviour. This behaviour affects its

\footnotetext{
'Wolfson School of Mechanical, Electrical and Manufacturing Engineering, Loughborough University, Leicestershire, UK

${ }^{2}$ University of Central Lancashire, Preston, Lancashire, UK
}

\section{Corresponding author:}

Nader Dolatabadi, Wolfson School of Mechanical, Electrical and Manufacturing Engineering, Loughborough University, Ashby Road, Loughborough, Leicestershire, LEI I 3TU, UK.

Email: N.Dolatabadi@lboro.ac.uk 
primary sealing function as well as its conjunctional friction, leading to increased harmful gas emissions. These often very contradictory requirements mean that a complex analysis is required to optimise the piston compression ring, potentially providing significant benefits in energy efficiency ${ }^{13}$ and emissions of the ICE. In fact, $3 \%-5 \%$ of the total ICE losses are associated with the piston compression ring-to-cylinder liner conjunction $^{14,15}$ and at least $2 \%-7 \%$ of engine losses are attributed to gas pressure leakage. ${ }^{16}$ Furthermore, the contribution of trapped unburnt fuel in the piston ring crevices due to gas blow-by is an important source of hydrocarbon emissions. ${ }^{12,16,17}$ Therefore, the dynamics and loss of sealing of a compression ring are root causes of hydrocarbon emissions with unburnt fuel entering its crevice volumes. Dealing with these complex issues can significantly reduce harmful emissions through optimal fuel usage and improved energy efficiency.

It is quite essential to accurately predict the tribological conditions in the piston ring-cylinder liner conjunction as a prelude for the determination of its frictional losses. Some early tribological studies were reported by Castleman ${ }^{18}$ and Furuhama, ${ }^{19}$ predicting lubricant film thickness in the piston compression ringto-cylinder liner conjunction. Dowson et al. ${ }^{20}$ also presented a 1D isothermal solution with assumed fully flooded inlet conditions. Later efforts included partial or mixed regimes of lubrication, ${ }^{21,22}$ including the more realistic inlet meniscus starvation. ${ }^{23,24}$

Based on the evaluation of Friction Mean Effective Pressure (FMEP), Akalin and Newaz ${ }^{22}$ showed reasonable agreement between their numerical predictions and in-situ measured friction by Furuhama and Sasaki. ${ }^{25}$ However, a more realistic analysis requires solution of 2D Reynolds equation, including assessment of conformability of the ring to the liner surface such as those conducted in $\mathrm{Ma}$ et al., ${ }^{26}$ Mishra et al., ${ }^{27,28}$ Fang et al., ${ }^{29}$ and Rahmani et al. ${ }^{30}$ The study by Rahmani et al. ${ }^{30}$ showed that mixed regime of lubrication is dominant for most of the power stroke. Piao and Gulwadi $^{31}$ also included the out-of-round bore effect, friction and blow-by. An important aspect in such analyses is the conformance of the compression ring to the bore surface. This is affected by the elastodynamics of the compression ring, subjected to gas pressure, ring tension, and contact forces and friction between the ring and the liner, as well as with the ring's retaining piston grooves. Rigid body dynamics of piston compression ring has been utilised to investigate gas flow, friction, dynamics and oil transport in the piston ring pack. $^{32,33}$ These studies were later extended to include more realistic flexible elastodynamics of the compression ring in a series of studies for its in-plane (radial) and out-of-plane (axial and twist) motions. ${ }^{33-37}$ Ring dynamics is essential in the study of both gas blow-by and frictional performance; an approach recently highlighted by Turnbull et al. ${ }^{38,39}$ Therefore, an integrated solution of gas dynamics through the crevices formed by an elastic ring and piston retaining grooves, together with a $2 \mathrm{D}$ tribological contact of ring-bore is required.

Another important issue is the inclusion of 2D mixed thermo-hydrodynamics of ring-liner contact, where it has also been shown that the lubricant contact temperature is primarily governed by the liner temperature, which clearly determines the lubricant viscosity, prevalent regime of lubrication and friction. ${ }^{40}$ Changes in liner wall temperature also influence the hydrocarbon (HC) and nitrogen oxide $\left(\mathrm{NO}_{\mathrm{x}}\right)$ emissions in an ICE. ${ }^{41}$ It is well established that the unburnt fuel mixture, trapped in the piston crevices, comprises $4 \%-8 \%$ of the fuel mixture inside the cylinder, which is comparable with the total $3 \%-10 \%$ unburnt fuel mixture during a combustion cycle. Hence, the trapped fuel mixture in piston crevices is considered as a major source of hydrocarbon emissions. $^{16,17}$

Hydrocarbon emissions are as the result of unburnt fuel within an internal combustion engine. The sources of hydrocarbon emissions are the formed crevices by the piston rings and their retaining piston lands/ grooves and the head gasket, valve seats and spark plug threads. ${ }^{17}$ Wang and Stone ${ }^{41}$ investigated the effect of wall temperature on hydrocarbon and nitrous oxide emissions. It was demonstrated that hydrocarbon emissions decreased with rising wall temperature, because of a combination of higher combustion temperature, as well as the wall temperature. Wang and Stone ${ }^{41}$ noted that especially under higher-load and higher-speed applications the nitrous oxide emissions increased with higher wall temperature. An increase in the liner wall temperature tends to reduce $\mathrm{HC}$ emissions and usually causes $\mathrm{NO}_{\mathrm{x}}$ to rise in high speed, high load applications. $\mathrm{NO}_{\mathrm{x}}$ emissions also vary with air-fuel ratio, combustion timing and duration. ${ }^{17,42}$ Rahmani et al. ${ }^{43}$ noted that an optimum liner temperature would allow a certain trade-off between emissions and generated friction. Higher temperatures reduce lubricant ingression into the combustion chamber which in turn decreases the rate of lubricant evaporation, and hence the emissions. Reducing oil flow in this manner is increasingly important as lubricants can absorb and desorb hydrocarbons from fuels, ${ }^{44}$ with adverse effects from some lubricant additives upon emissions. ${ }^{45}$ This is because certain elements in the lubricant additive package, such as phosphorus, zinc, or sulphur can adversely affect the exhaust catalysts, which in turn reduces their efficiency, rising the emissions from the vehicle. In addition, these lubricant additives can cause formation of sulphates, downstream of a catalysed particulate filter or other oxidation catalysts. Furthermore, the importance of lubricant temperature and reducing lubricant warm up time on mechanical efficiency and $\mathrm{CO}$ emissions highlights the importance of a lubricant upon engine efficiency and emissions. ${ }^{46}$

The foregoing discussions demonstrate the need for a comprehensive integrated ring elastodynamics, gas flow dynamics and ring-liner mixed thermohydrodynamics analysis to study the power losses and 
emissions of an engine under normal operating conditions. This is also important when a vehicle is subjected to the use of new technologies with an increasing uptake in modern vehicle fleet such as cylinder deactivation (CDA). This is the integrated approach undertaken in this paper, which extends the work recently reported by Morris et al., ${ }^{47}$ which does not include the elastodynamics of compression ring and the associated gas blow-by. The current integrated study of ring elastodynamics and gas blow-by is original contributions and has not hitherto been reported in the literature, particularly with the inclusion of CDA.

\section{Outline of methodology}

\section{Piston ring in-plane flexible dynamics}

The coupled equations of motion for small deformations of a thin beam with negligible shearing deformation are given by ${ }^{48}$ :

$$
\begin{aligned}
& \frac{\partial F}{\partial \theta}+P+f_{R} R=\rho_{2} A_{2} R_{2} \frac{\partial^{2} u}{\partial t^{2}} \\
& \frac{\partial P}{\partial \theta}-F+f_{p} R=\rho_{2} A_{2} R_{2} \frac{\partial^{2} w}{\partial t^{2}}
\end{aligned}
$$

where, $\rho_{2}, A_{2}, R_{2}$ and $\theta$ are the density of the ring material, the ring cross-sectional area, the ring radius and the circumferential position around the ring periphery. Furthermore, the applied radial and tangential in-plane forces acting on the ring circumference are given by $f_{R}$ and $f_{p}$, whilst $u$ and $w$ denote the radial and circumferential directions (Figure 1). Neglecting rotary inertia about the cross-sectional centreline, the moment equation about the middle plane of the ring segment is obtained, based on the equilibrium of forces, thus:

$$
F=-\frac{E_{2} I_{2}}{R_{2}{ }^{3}}\left(\frac{\partial w}{\partial \theta}+\frac{\partial^{2} u}{\partial \theta^{2}}\right)
$$

where, $I_{2}$ is the second area moment of inertia, and similarly the equilibrium condition in the axial direction yields:

$$
P=\frac{E A}{R}\left(-u+\frac{\partial w}{\partial \theta}\right)
$$

The in-plane dynamics equations (1) and (2) are discretised using central difference discretisation, based on the finite difference method (FDM) ${ }^{38}$ The solution to the coupled in-plane elastodynamic equations of motion (1) and (2) can then be found based on either an analytical ${ }^{35}$ or a numerical method. ${ }^{38}$

\section{Tribology of piston ring - cylinder liner contact}

The piston compression ring-cylinder liner contact is subjected to mixed hydrodynamic regime of lubrication for much of the piston cycle. The viscous contact pressure, $p$, is predicted for a compressible fluidic medium using Reynolds equation:

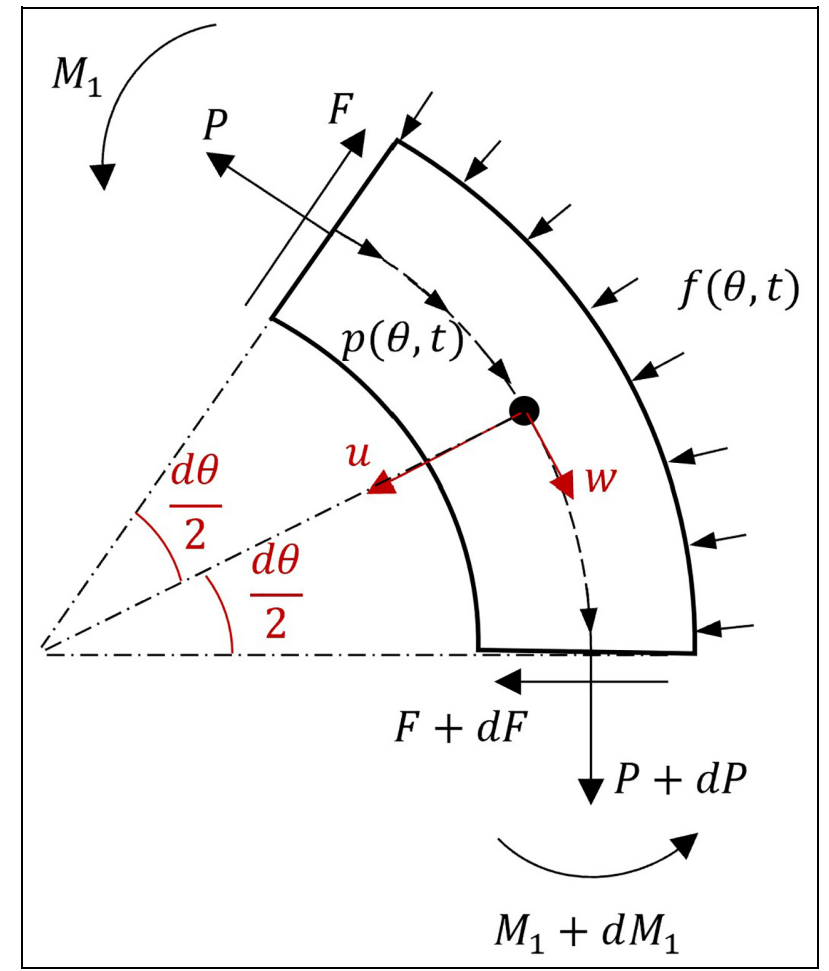

Figure I. Forces and moments acting on an element of a ring.

$$
\frac{\partial}{\partial x}\left(\frac{\rho h^{3}}{6 \eta} \frac{\partial p}{\partial x}\right)+\frac{\partial}{\partial y}\left(\frac{\rho h^{3}}{6 \eta} \frac{\partial p}{\partial y}\right)=\frac{\partial(\rho U h)}{\partial x}+2 \frac{\partial(\rho h)}{\partial t}
$$

where, $\rho$ is the lubricant density, and $\eta$ the dynamic viscosity accounts for the piezo-viscous action of the lubricant. $U$ is the sliding velocity of the piston ring relative to the cylinder liner surface. The lubricant film thickness, $h$, is obtained as:

$$
h(x, y, t)=h_{m}(t)+h_{s}(x)+\Delta(y, t)
$$

where, $h_{s}$ is the axial profile of the ring contact face, $\Delta$ is the circumferential ring deflection affected by its in-plane ring dynamics, whilst the localised Hertzian contact deflection is neglected owing to insufficient generated pressures. It is shown that for typical ring pressures in road vehicle gasoline engines, the localised pressure-induced deflection at the ring-cylinder interface is negligible. ${ }^{27,28}$

Piston axial kinematics is used to approximate the sliding (axial) velocity, $U$, at the ring-cylinder interface $^{49}$ where the small fluctuations in the velocity due to the ring flutter are neglected:

$$
U(\varphi) \cong-r \omega\left(\sin \varphi+\frac{r}{2 l} \sin 2 \varphi\right)
$$

The modified Dowson and Higginson relationship is used to account for the variation of lubricant density with generated contact pressure and temperature ${ }^{50,51}$ :

$$
\rho=\rho_{0}\left[1+\frac{6 \times 10^{-10}\left(p-P_{a t m}\right)}{1+1.7 \times 10^{-9}\left(p-P_{a t m}\right)}\right]\left[1-\beta\left(T-T_{0}\right)\right]
$$


The effect of pressure and temperature on lubricant viscosity is taken into account through the relationship first developed by Roeland ${ }^{52}$ and later modified by Houpert ${ }^{53}$ as:

$$
\begin{aligned}
& \eta=\eta_{0} \\
& \exp \left\{\left(\ln \eta_{o}+9.67\right)\left[\left(\frac{T-138}{T_{0}-138}\right)^{-S_{0}}\left(1+\frac{p-p_{\text {atm }}}{1.98 \times 10^{8}}\right)^{Z}-1\right]\right\}
\end{aligned}
$$

The reference viscosity, $\eta_{0}$, is evaluated at the ambient conditions and $Z=\alpha_{0} C_{p} / \ln \left(\eta_{0} / \eta_{\infty}\right)$ and $S_{0}=\beta_{0}$ $\left(T_{0}-138\right) / \ln \left(\eta_{0} / \eta_{\infty}\right)$ where, the atmospheric coefficients $\alpha_{0}$ and $\beta_{0}$, are the pressure-viscosity and temperature-viscosity indexes, respectively. The lubricant contact temperature is primarily governed by the liner temperature. ${ }^{40}$ Therefore, liner temperature is used to determine the lubricant effective viscosity in the current analysis.

The contact load is carried partially by the viscous lubricant, $W_{h}$, which is obtained by integrating the generated hydrodynamic pressures over the contact area, and partially by the counter face interacting asperities, $W_{a}$. During piston reversals, contact is momentarily starved of lubricant and the surface asperities carry most of the applied load. Assuming an equivalent rough surface contacting a smooth plane, and that the asperities' heights follow a Gaussian distribution, the share of contact load carried by direct contact of surfaces, $W_{a}$ can be obtained using the Greenwood and Tripp model $^{54}$ as:

$$
\begin{gathered}
W=W_{h}+W_{a}=\iint p d A+\frac{16 \sqrt{2}}{15} \pi(\xi \kappa \sigma)^{2} \\
\sqrt{\frac{\sigma}{\kappa}}\left(\frac{1-v_{1}^{2}}{E_{1}}+\frac{1-v_{2}^{2}}{E_{2}}\right)^{-1} A F_{5 / 2}(\lambda)
\end{gathered}
$$

where, $A$ is the ring-bore conjunction apparent contact area, $\xi \kappa \sigma$ is the composite surface roughness parameter found using topographical measurements. $\sigma, \kappa$ and $\xi$ are composite root mean square (rms) roughness, average radius of curvature of asperity tips and density of asperity peaks per unit area of surfaces, respectively. $\lambda=h / \sigma$ represents the Stribeck lubricant film ratio. The statistical function, $F_{5 / 2}$, is approximated by a polynomial fit $^{55}$ :

$$
\begin{aligned}
& F_{5 / 2}(\lambda)= \\
& \left\{\begin{array}{cc}
-0.0046 \lambda^{5}+0.0574 \lambda^{4}-0.2958 \lambda^{3} & \\
+0.7844 \lambda^{2}-1.0776 \lambda+0.6167 ; & \text { for } \lambda \leqslant \lambda_{c}=2.224 \\
0 ; & \text { for } \lambda>\lambda_{c}=2.224
\end{array}\right.
\end{aligned}
$$

The total friction takes into account viscous friction, $f_{v}$, due to viscous shear which varies with the lubricant pressure gradient, as well as the relative sliding velocity and losses due boundary friction originated from the surface asperity interactions, $f_{b} .{ }^{56}$ $f_{t}=f_{v}+f_{b}=\left| \pm \frac{h}{2} \vec{\nabla} p+\overrightarrow{\mathrm{V}} \frac{\eta}{h}\right|\left(A-A_{e}\right)+\left(\tau_{0} A_{e}+\zeta W_{a}\right)$

where, $\tau_{0}$ and $\zeta$ are the characteristic Eyring shear stress of the oil ${ }^{57}$ and coefficient of boundary shear strength of the softer counter face, respectively. The latter is determined through use of atomic force microscope (AFM) in lateral force mode (LFM) ${ }^{56}$ The asperity contact area, $A_{e}=\pi^{2}(\xi \kappa \sigma)^{2} A F_{2}(\lambda)^{54}$ and the statistical function, $F_{2}$ based on a polynomial curve fit is: ${ }^{55}$

$$
\begin{aligned}
& F_{2}(\lambda)= \\
& \left\{\begin{array}{cc}
-0.0018 \lambda^{5}+0.0281 \lambda^{4}-0.1728 \lambda^{3} & \\
+0.5258 \lambda^{2}-0.8043 \lambda+0.5003 ; & \text { for } \lambda \leqslant \lambda_{c}=2.295 \\
0 ; & \text { for } \lambda>\lambda_{c}=2.295
\end{array}\right.
\end{aligned}
$$

Heat is generated within the contact due to friction. As a result, the contact temperature increases in addition to the surface temperature rise due to combustion. It is shown that under hot operating conditions, the contact temperature is usually dominated by the temperature of the cylinder liner ${ }^{40}$ and the thermal effect of friction is relatively inappreciable. ${ }^{43,58}$ Therefore, in the current study it is assumed that the contact temperature is the same as the surface temperature of the cylinder liner.

\section{Combustion gas blow-by and exhaust emissions}

The combustion gases flow into and out of the pistonpiston ring crevices during a typical engine cycle. Therefore, some engine power loss can be associated with the gas blow-by as is highlighted in Turnbull et al. ${ }^{39}$ To evaluate the leakage power loss a gas control volume model needs to be utilised to predict the mass flows through these crevices as shown schematically in Figure 2.

Several methods for gas blow-by have already been presented in the literature. ${ }^{16,39,59,60}$ The gas blow-by model used in the current study is that presented in Turnbull et al. ${ }^{39}$ Therefore, the details are repeated here for the sake of brevity. The associated power loss is obtained as ${ }^{39,61}$ :

$$
P_{l}=\dot{m} \frac{\gamma_{s}}{\left(\gamma_{s}-1\right)} R T_{U}\left[1-\left(\frac{P_{D}}{P_{U}}\right)^{\frac{\left(\gamma_{s}-1\right)}{\gamma_{s}}}\right]
$$

The mass fraction of burnt fuel in the combustion chamber at a point during the engine cycle is determined $^{62}$ as:

$$
\operatorname{MFB}(t)=\frac{p_{\text {cyl,fired }}(t)}{p_{\text {cyl, motored }}(t)}-1
$$

where, $p_{c y l, \text { fired }}$ is the fired cylinder pressure, $p_{c y l, \text { motored }}$ is the motored cylinder pressure and $M F B$ is the fraction of burnt fuel. Leonhardt et al. ${ }^{63}$ showed that this mass fraction is in good agreement with the thermodynamic analysis of Hohenberg and Killmann. ${ }^{64}$ 
The volume of unburnt gas within the combustion chamber is ${ }^{16}$ :

$$
V_{u}(t)=V_{0}\left(\frac{P_{0}}{P(t)}\right)^{\frac{1}{\gamma}}(1-M F B(t))
$$

where, $V_{u}$ is the volume of unburnt fuel, $P_{0}$ is the precombustion pressure, $V_{0}$ is the cylinder volume that corresponds to $P_{0}$, and $P(t)$ is the instantaneous cylinder pressure.

A number of assumptions are made:

(1) There is steady mass flow rate per unit area into the piston crevices

(2) The mean flame front location is defined by the burnt mass fraction of the fuel

(3) The mean flame front can be approximated to a plane orthogonal to the piston crown surface

(4) The unburnt charge is compressed in an isentropic manner

With these simplifying but reasonable assumptions, a relationship can be found between the volume of unburnt fuel mix and the total swept cylinder volume as $^{16}$ :

$$
V_{u}(t)=\left[\frac{2 L_{u}(t)}{B}-\sin \left(\frac{2 L_{u}(t)}{B}\right)\right] V_{t}(t)
$$

where, $V_{t}(t)$ is the total cylinder volume, $\mathrm{B}$ (Figure 2) is the bore diameter and $L_{u}$ is the proportion of the crevice length exposed to the unburnt mixture.

The unburnt mass flow rate into the crevice A (Figure 2) from the combustion chamber is therefore ${ }^{16}$ :

$$
\dot{m}_{u}=\dot{m}_{a}\left(\frac{L_{u}}{L_{t}}\right)
$$

where, $L_{t}$ is the total crevice length.

The burnt portion of the mass flow rate into the crevice $\mathrm{A}$ from the combustion chamber is therefore: ${ }^{13}$

$$
\dot{m}_{b}=\dot{m}_{a}\left(\frac{L_{b}}{L_{t}}\right)
$$

where, $L_{b}$ is the portion of the crevice length exposed to the burnt gas.

Shayler et al. ${ }^{17}$ developed relationships between the mass flow rate of the fuel and any pollutants for various types of automotive gasoline engines.

The ratio of $\mathrm{CO}$ mass flow rate to mass flow rate of fuel supplied $\left(f n_{1}\right)$ is given as: ${ }^{17}$

$$
f n_{1}(\phi)=\left\{\begin{array}{l}
e^{\left(a+b \phi^{2}\right)} \text { if } \phi<1 \text { and } a=-8.395, b=5.5181 \\
a+b \phi \text { if } \phi \geqslant 1 \text { and } a=-2.725, b=2.78
\end{array}\right.
$$

where, $\phi$ is the equivalence ratio:

$$
\phi=\frac{A F R_{\text {stoich }}}{A F R}
$$

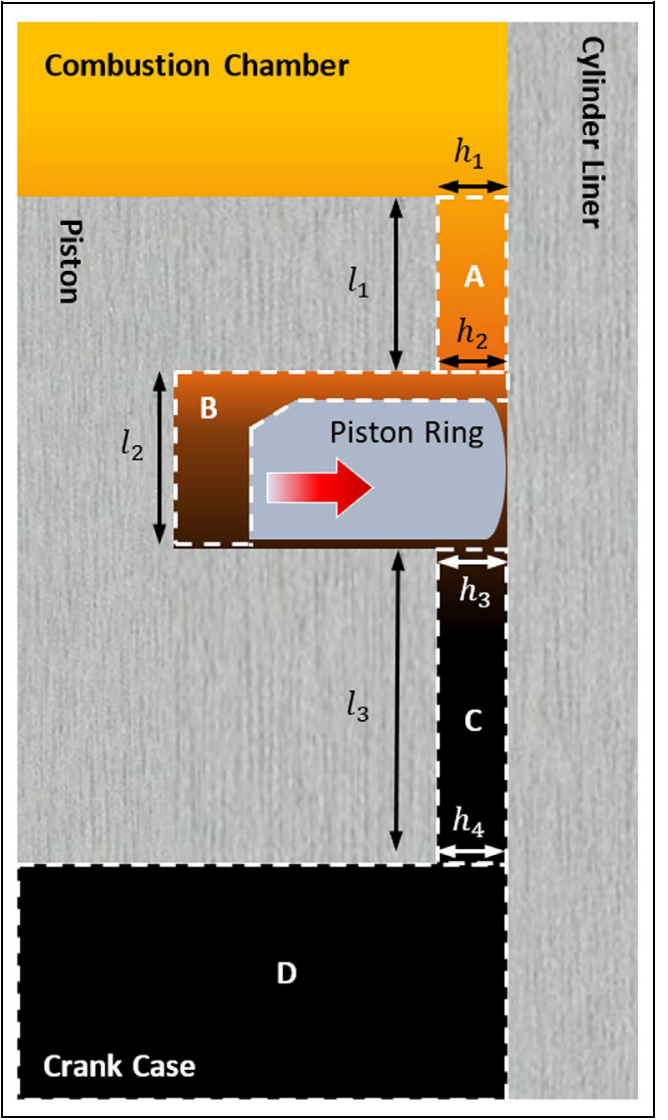

Figure 2. Schematic representation of the control volumes in piston crevices.

$\mathrm{CO}$ predictions are a primary function of the equivalence ratio and not the engine operating conditions. ${ }^{17,61}$ The index of CO emissions is determined as:

$$
E I_{C O}=f n_{1}(\phi)
$$

The $\mathrm{HC}$ emissions are related to the equivalence ratio as:

$$
f n_{2}(\phi)=a+b \phi+\frac{c}{\phi^{2}}
$$

where, $a, b$ and $c$ are constants given as -0.00484 , 0.004326 and 0.0013313 respectively. ${ }^{61}$

The spark timing for the Minimum Advance for Best Torque Delivery (MBTD) is given for various exhaust gas recirculation (EGR) in Shayler et al. ${ }^{17}$ for different engine types. The relationship between $\mathrm{HC}$ emissions and MBTD is:

$$
f n_{3}(M B T D)=\left\{\begin{array}{lc}
1 & \text { if } M B T D \leqslant 0 \\
1+a(M B T D)^{2} & \text { if } M B T D>0 \text { and } \\
a=f n_{4}(\phi) f n_{5}(E G R)
\end{array}\right.
$$

where, $f n_{4}(\phi)$ is a function of the equivalence ratio, hence: 


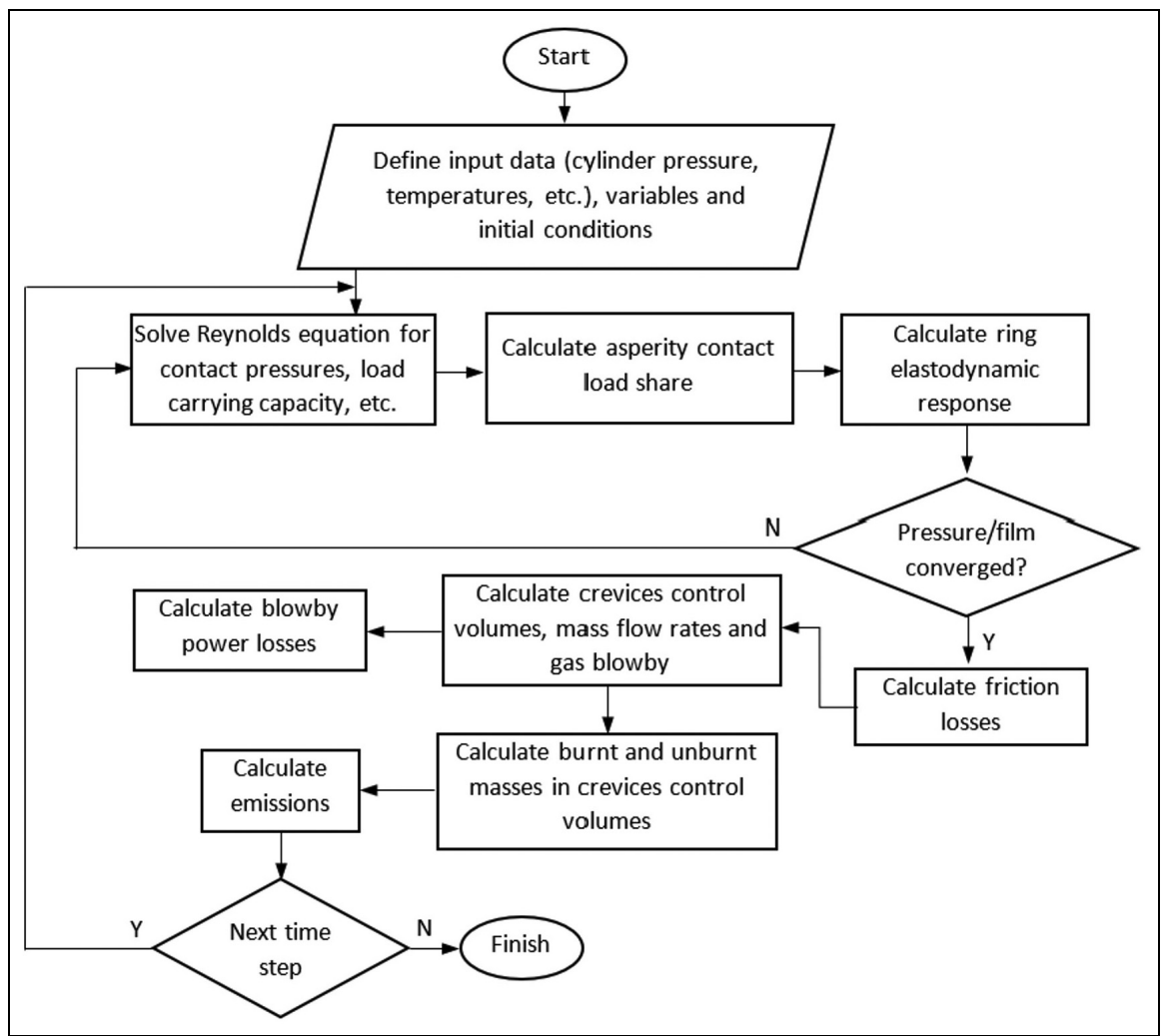

Figure 3. Computational flow chart.

$$
f n_{4}(\phi)=a+\frac{b}{\phi}+c \phi^{2}
$$

The constants $a, b$ and $c$ are $-0.00326,0.0002134$ and 0.0016489 respectively, and $f n_{5}(E G R)$ is a function of exhaust gas recirculation as:

$$
f n_{5}(E G R)=a+b(E G R)+c(E G R)^{2}
$$

where $a, b$ and $c$ are constants with the values 1 , -0.016643 and -0.002866 respectively.

$\mathrm{HC}$ emissions index is therefore determined as ${ }^{17}$ :

$$
E I_{H C}=G F R f n_{2}(\phi) f n_{3}(M B T D)
$$

where, GFR is the gas fuel ratio dependent on the air/ fuel ratio. ${ }^{17}$

$\mathrm{NO}_{\mathrm{x}}$ emissions are related to the air/fuel ratio $(A F R)$ and burnt mixture fraction, $x_{b}$, as:

$$
f n_{6}\left(A F R, x_{b}\right)=\left[\frac{a+b(A F R)+e(A F R)^{2}}{1+b(A F R)+d(A F R)^{2}}\right] \exp \left(\frac{x_{b}}{0.13}\right)
$$

where $a, b, c, d$ and $e$ are constants with the values $-0.00326, \quad-0.12489, \quad-7.401 \times 10^{-5}, \quad 0.004$ and $4.0717 \times 10^{-5}$, respectively.

$\mathrm{NO}_{\mathrm{x}}$ emissions are related to the spark ignition timing (MBTD) through:

$$
f n_{7}(M B T D)=a+b(M B T D)+c(M B T D)^{2}
$$

where, the constants $a, b$ and $c$ are $1,-0.021$ and -0.00051 , respectively.
$\mathrm{NO}_{\mathrm{x}}$ emissions index is therefore predicted as ${ }^{17}$ :

$$
E I_{N O_{x}}=f n_{6}\left(A F R, x_{b}\right) f n_{7}(M B T D)
$$

\section{Solution methodology}

The integrated multi-physics model in the current study includes the flexible ring elastodynamics, mixed thermo-hydrodynamics of ring-liner contact and a gas blow-by model. The blow-by model is an expansion of that detailed in Turnbull et al. ${ }^{39}$ to include predictions of unburnt and burnt fuel in the piston crevices, as well as exhaust gas emissions (Figure 3). The overall integrated multi-physics model is also used to study the effect of CDA.

The following solution procedure is used:

Step 1: Advance the crank angle, commencing from $0^{\circ}$ Step 2: Solve Reynolds equation and elastic film shape with rheological state equations for the ring-liner contact, determining pressure distribution and lubricant film thickness.

Step 3: Determine the hydrodynamic reaction and asperity load, thus the total contact load.

Step 4: With net applied forces, calculate ring deformation and velocity profiles

Step 5: Determine viscous and boundary friction, thus total friction and frictional power loss.

Step 6: Determine gas pressures in the control volumes as well as gas leakage

Step 7: Return to step 1. 
Table I. Engine and lubricant (SAE IOW40) specifications.

\begin{tabular}{|c|c|c|}
\hline Parameter & Value & Unit \\
\hline Bore radius & 44.52 & $\mathrm{Mm}$ \\
\hline Ring material & Steel & - \\
\hline Crank-pin radius & 39.75 & $\mathrm{Mm}$ \\
\hline Connecting rod length & 138.1 & $\mathrm{Mm}$ \\
\hline Liner material & Cast Iron & - \\
\hline Lubricant density & $833.8\left(@ 40^{\circ} \mathrm{C}\right)$ & $\mathrm{kg} / \mathrm{m}^{3}$ \\
\hline Lubricant viscosity & $59.99\left(@ 40^{\circ} \mathrm{C}\right)$ & $\mathrm{mPa} . \mathrm{s}$ \\
\hline $\begin{array}{l}\text { Lubricant thermal } \\
\text { expansion coefficient }\end{array}$ & $6.5 \times 10^{-4}$ & $\mathrm{~K}^{-1}$ \\
\hline $\begin{array}{l}\text { Lubricant piezo-viscous } \\
\text { coefficient }\end{array}$ & $2 \times 10^{-8}$ & $\mathrm{~Pa}^{-1}$ \\
\hline $\begin{array}{l}\text { Lubricant thermo-viscous } \\
\text { coefficient }\end{array}$ & 0.04 & $\mathrm{~K}^{-1}$ \\
\hline Roughness parameter $(\xi \kappa \sigma)$ & 0.04 & - \\
\hline $\begin{array}{l}\text { Measure of asperity } \\
\text { gradient }(\sigma / \kappa)\end{array}$ & 0.001 & - \\
\hline $\begin{array}{l}\text { Coefficient of boundary } \\
\text { shear strength }\end{array}$ & 0.17 & - \\
\hline $\begin{array}{l}\text { Liner Young's elastic } \\
\text { modulus }\end{array}$ & 92.3 & $\mathrm{GPa}$ \\
\hline Liner Poisson's ratio & 0.211 & - \\
\hline $\begin{array}{l}\text { Ring Young's elastic } \\
\text { modulus }\end{array}$ & 203 & GPa \\
\hline Ring Poisson's ratio & 0.3 & - \\
\hline Ring axial height & 1.15 & $\mathrm{Mm}$ \\
\hline Ring radial thickness & 3.5 & $\mathrm{Mm}$ \\
\hline Free ring end-gap & 10.5 & $\mathrm{Mm}$ \\
\hline Ring density & 7850 & $\mathrm{~kg} / \mathrm{m}^{3}$ \\
\hline
\end{tabular}

\section{Engine specifications}

The developed model comprises piston ring elastodynamics, tribology of contact between the ring and liner, and gas dynamics. Therefore, it is a multi-physics model. In addition, thermal effects are incorporated in both lubricant rheology and flow of blow-by gasses.

In the current study, measured liner temperature is used in the analysis, whilst the heat generated due to friction and its conduction and convection from the contact is neglected. It must be noted that the compressible gas flow through the crevices consumes a relatively small portion of expended fuel energy. This can result in an unburnt fuel mixture, which is a major source of hydrocarbon emissions. ${ }^{16}$

A 4-cylinder, 4-stroke spark ignition engine is studied here. Engine specifications pertinent to the current analysis are listed in Table 1. Figure 4 shows the measured cylinder pressure and liner temperature for the three cases of (i)- a cylinder under normal engine operating condition, (ii)- an active cylinder under CDA and (iii)- a deactivated cylinder. Under normal engine operation all the four cylinders remain operational, whilst during cylinder deactivation two cylinders are active and the other two are deactivated. The deactivated cylinders have a closed inlet and exhaust valves, resulting in compression and expansion of the cylinder residual charge content. The active cylinders experience higher combustion pressures and cylinder wall temperatures to maintain the desired output power. The liner wall temperature is measured during steady state operating condition, where it is largely stable, with the main temperature variation noted between the top and bottom of the cylinder liner, rather than any transient variations between successive cycles.

\section{Results and discussions}

Figure 5 shows the minimum lubricant film thickness variation for the piston compression ring-to-cylinder liner contact for an engine cycle. The film thickness for an active cylinder under CDA, a deactivated cylinder and a cylinder under normal engine operation are presented. The regime of lubrication falls into mixed and boundary conditions at the vicinity of Top Dead Centre (TDC) and Bottom Dead Centre (BDC) during piston reversals and during the power stroke owing to a reduced film thickness. There is a significant reduction in the film thickness for the active cylinder under CDA when compared with the cylinder under normal operation. This is because of the combination of a higher combustion pressure and liner temperature.

The corresponding predicted friction under different cylinder operating conditions is shown in Figure 6. The

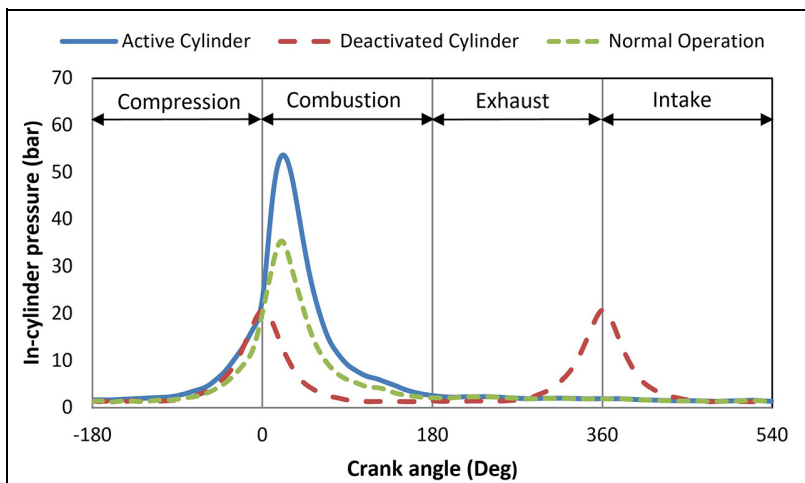

(a)

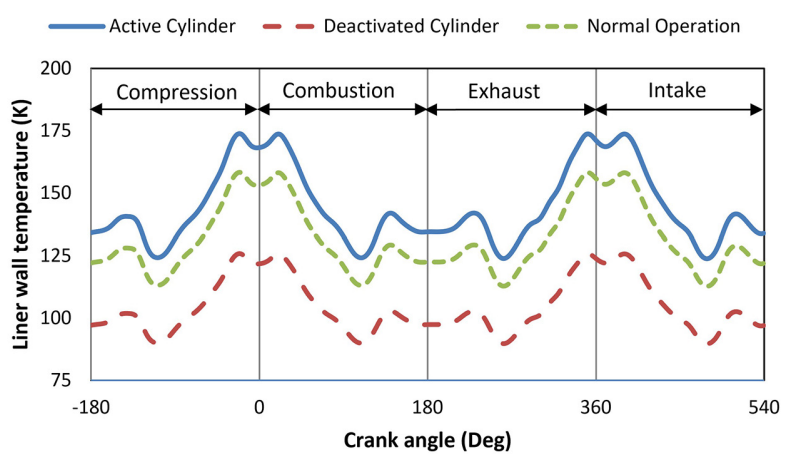

(b)

Figure 4. Measured engine data: (a) in-cylinder pressure, and (b) liner wall temperature at $3000 \mathrm{rpm}$ and full load. ${ }^{47}$ 


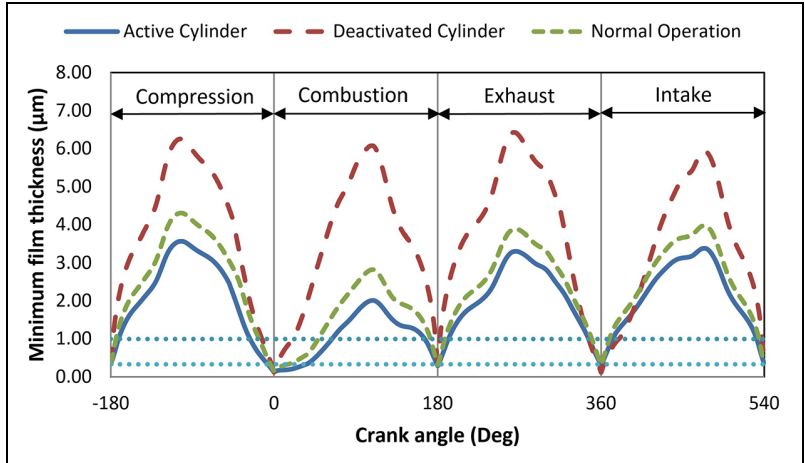

Figure 5. Compression ring-liner contact minimum film thickness variation in an engine cycle under different conditions.

reduction in film thickness for the active cylinder of the engine subjected to CDA promotes increased boundary friction well into the power stroke, whilst boundary friction under normal engine operating condition is significantly reduced. The deactivated cylinder has the most boundary friction at the TDC, which is rapidly decreased with an increasing sliding velocity, promoting an increased rate of lubricant entrainment into the contact conjunction. High boundary friction occurs because the combustion pressure within the deactivated cylinder at TDC (Figure 4(a)) is higher than for both the active cylinder of a CDA engine and the cylinder under normal engine operating mode. The combination of the increased boundary friction in an active cylinder of CDA engine and the increased boundary friction at the TDC for deactivated cylinders demonstrates the potential for higher wear in cylinder operating under CDA due to a severely reduced lubricant film thickness. This would required further investigations.

The corresponding frictional power losses are shown in Figure 7(a). There are significant power losses during the combustion stroke for an active cylinder due to prevalent boundary and mixed lubrication conditions. The power loss predictions for an active cylinder of a CDA operated engine are low during the remaining engine strokes because of a higher liner temperature, reducing the lubricant viscosity thus viscous frictional losses. On the other hand, there is significant viscous friction for the deactivated cylinder throughout the engine cycle due to its lower liner temperature, thus a higher lubricant viscosity. This finding supports the work reported by Di Battista and Cipollone ${ }^{46}$ who outlined the importance of lubricant temperature upon frictional losses. Under normal engine operation mode there is high friction during the power stroke and a sizeable contribution by viscous friction for the remaining engine strokes. Unbalanced cooling is often seen as a drawback for engines operating under CDA. The results here demonstrate that this is the case in frictional predictions, with the lower liner temperatures increasing the viscous frictional losses for the deactivated cylinder. For the active cylinder with higher liner temperature boundary friction increases. Figure 7(b) shows the difference in cyclic friction for an engine operating

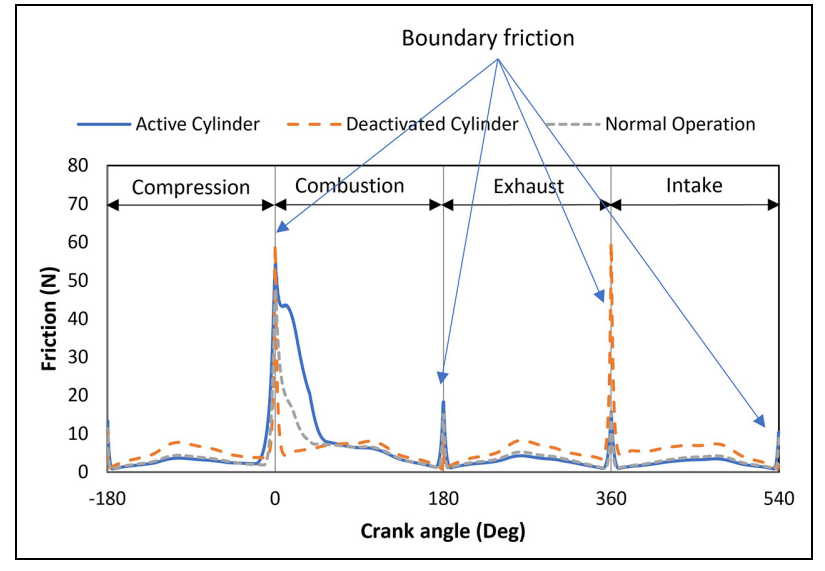

Figure 6. Predicted cyclic ring-liner friction in an engine cycle under different running conditions.

normally and one operating under cylinder deactivation, which is similar to the results reported in the literature. $^{47}$

Power loss due to gas leakage in the form of blowby through the piston ring crevices is shown in Figure 8(a). These are the highest for an active cylinder under CDA because of the higher operating combustion pressures. The deactivated cylinder also has high gas leakage power losses due to the cylinder compressing the gasses twice during an engine cycle. Figure 8(b) shows an increase in gas leakage losses per cycle for an engine operating under CDA. Namazian et al. ${ }^{16}$ observed that piston ring crevice gas flow power loss can be at least $2 \%-7 \%$ of fuel energy, depending on the engine type. Gas power losses are likely to rise exponentially with any significant ring flutter. The current model does not include other rings within the ring-pack assembly. Therefore, it is likely that the gas pressure losses are somewhat overpredicted. Namazian and Heywood ${ }^{16}$ showed that less than $20 \%$ of the unburnt fuel mixture mass is blown into piston compression ring crevices, reaching the crevices of the second ring. Hence, it is anticipated that emissions are mainly affected by the behaviour of the top compression ring.

The total compression ring losses due to friction and gas leakage for the engine operating normally and under cylinder deactivation are shown in Figure 9. There is an increase of approximately $60.3 \mathrm{~W}$ per cycle under cylinder deactivation, representing an increase in losses of around $21.7 \%$. This represents a significant increase in losses per cycle. However, these losses are small in comparison to the gains in fuel economy due to an engine operating under CDA. ${ }^{9-11}$ However, these losses are not often taken into account in assessing engine performance as they should be under CDA.

\section{Emissions}

The total mass flow rate of unburnt fuel and burnt gas from the combustion chamber into the piston ring-pack 


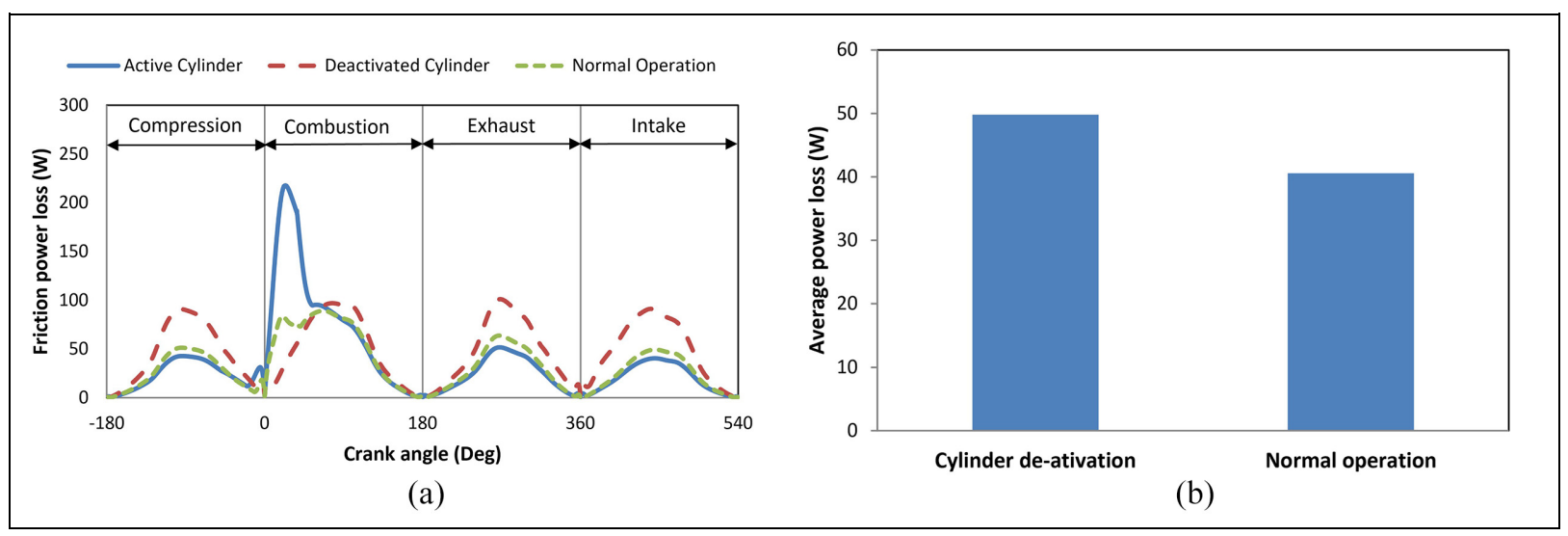

Figure 7. Frictional power loss predictions of ring-liner contact under different cylinder operating conditions: (a) per crank angle, and (b) average per cycle.

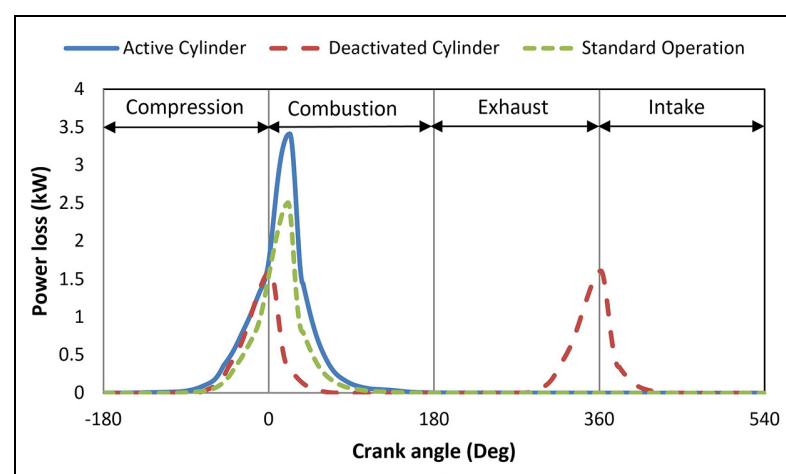

(a)

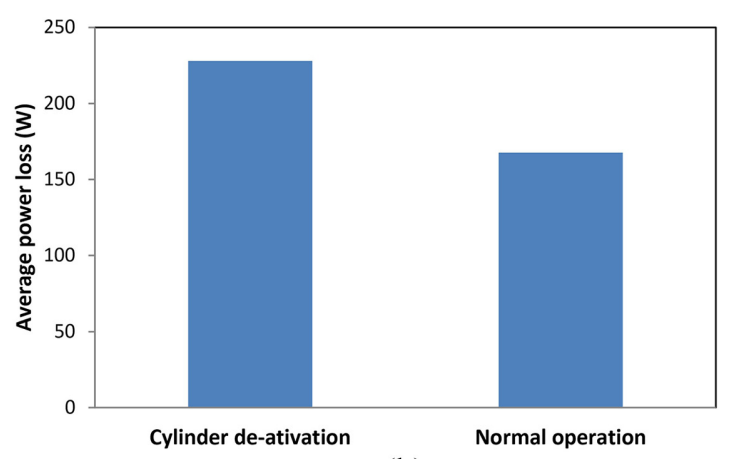

(b)

Figure 8. Gas leakage power loss predictions in an engine cycle under normal operation and cylinder deactivation: (a) per crank angle, and (b) average per cycle.

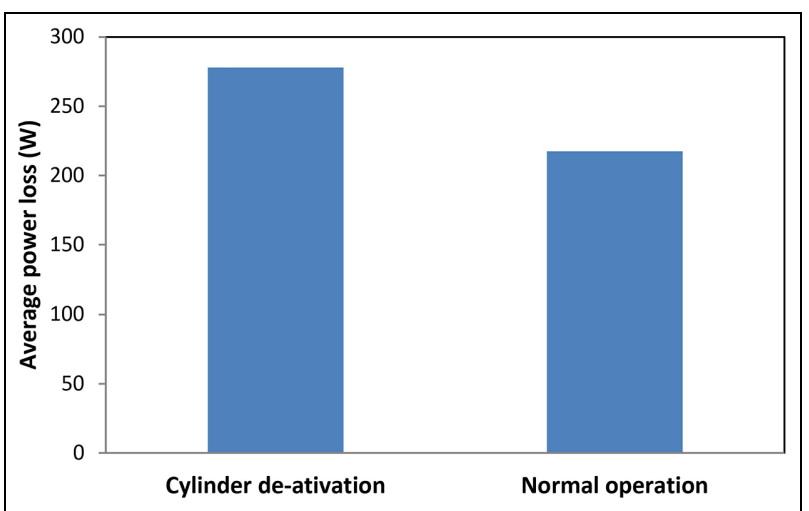

Figure 9. Average combined frictional and gas leakage power losses for an engine operating normally and subject to CDA.

crevices in the current predictive analysis is shown in Figure 10. The total unburnt fuel flow rate into the piston ring-pack assembly is significantly reduced under CDA as one would expect. The results show that combination of the higher cylinder wall temperature, a reduction in total fuel burnt and a decrease in unburnt fuel gas flow rate constitute a reduction in hydrocarbon emissions from the piston crevices for an engine operating under CDA.

Figure 10 shows that most of the gas flow into the piston crevices contains unburnt fuel. Absorption and desorption of unburnt fuel into the lubricating oil can contribute to emissions, ${ }^{65}$ as well as lubricant contamination. ${ }^{66}$ During excessive ring flutter, it is likely that there would be an increase in the gas flowing through the piston compression ring into the crank case. The simple analytical method expounded here to approximate the unburnt and burnt gases flowing through the ring pack provides a convenient and efficient analysis approach without the need for a more cumbersome computational fluid dynamics (CFD) simulations approach.

During operation an engine utilises a feedback loop to ensure that the air-fuel mixture is close to stoichiometric condition. The engine analysed in the current study acts under a constant full load condition, thus not reacting to any load transience. ${ }^{47}$ Therefore, it can be considered to be operating around the stoichiometric air-fuel ratio. Under these conditions, Figure 11 shows that $\mathrm{CO}, \mathrm{HC}$ and $\mathrm{NO}$ exhaust emissions are reduced when the engine is subject to $\mathrm{CDA}$, similar to 


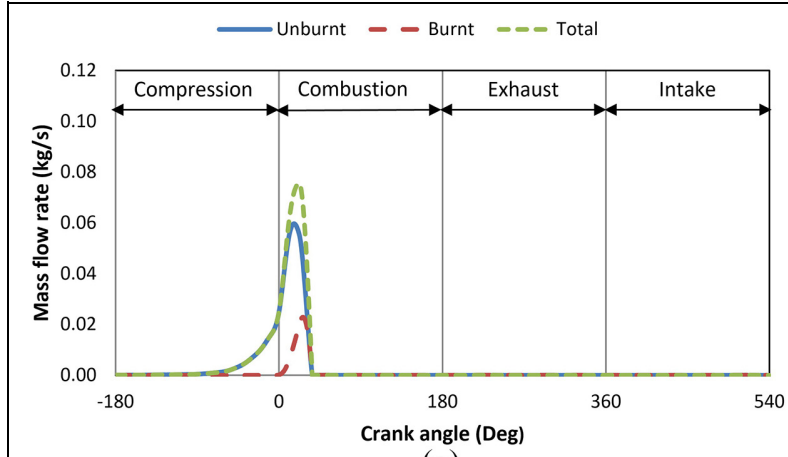

(a)

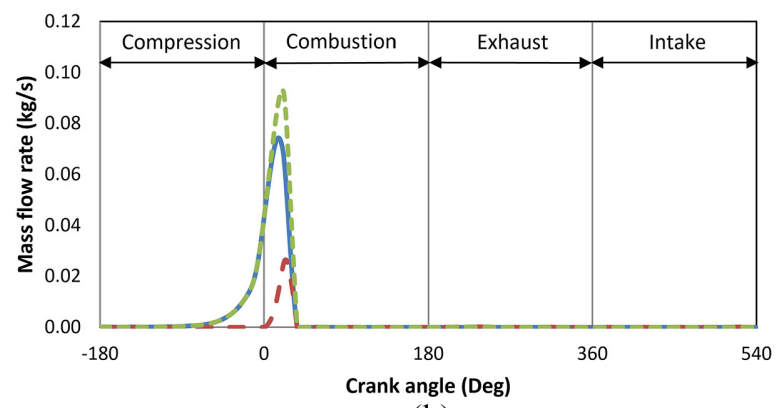

(b)

Figure 10. Total burnt and unburnt gas leakage from the combustion chamber into the piston ring-pack top crevice volume in an engine with: (a) CDA, and (b) normal operation.

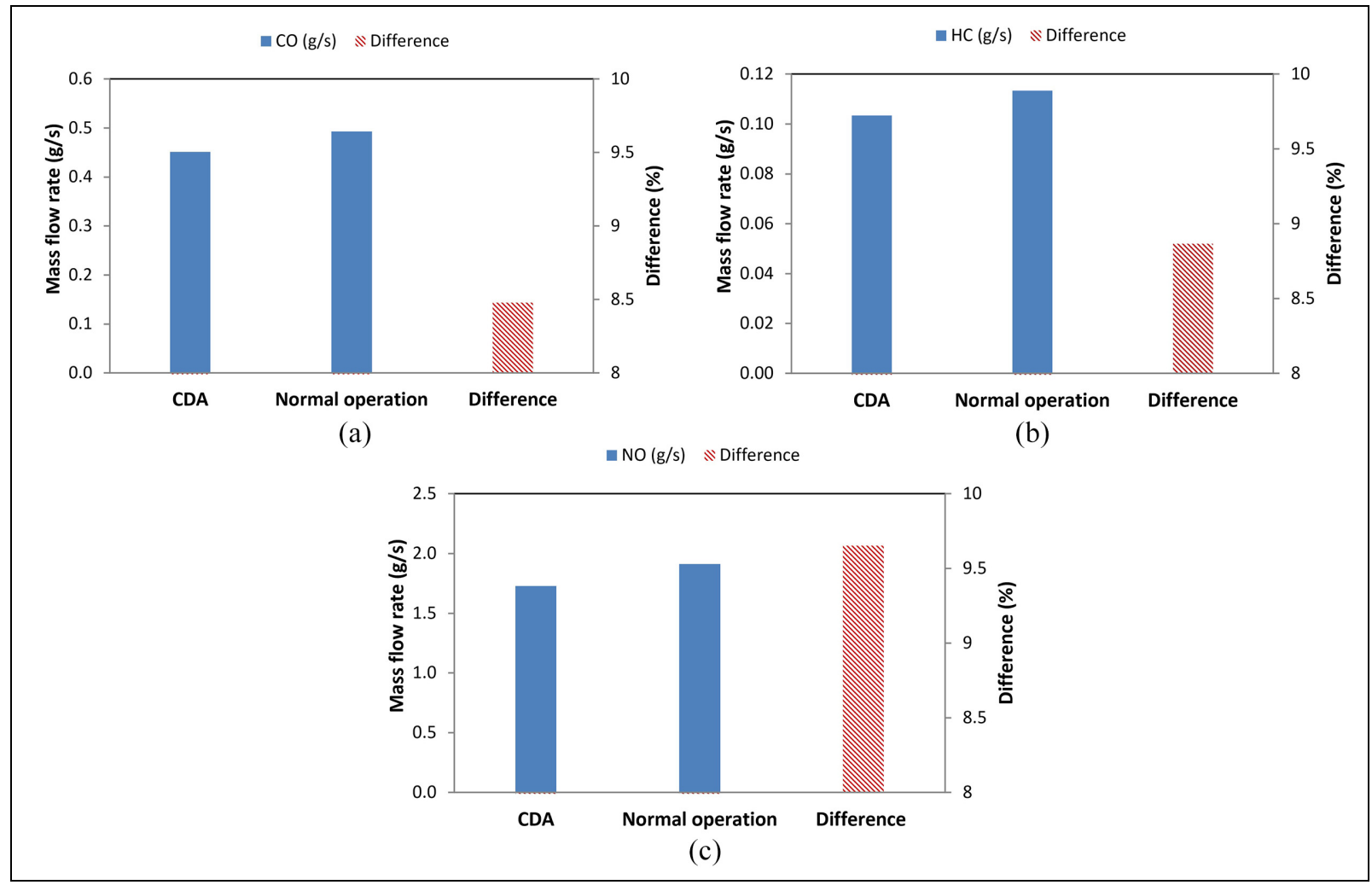

Figure II. Predicted emissions for an engine under normal operation and an engine with CDA: (a) CO, (b) HC and (c) NO.

observations reported in. ${ }^{9,11}$ The reduction in predicted hydrocarbon emissions with CDA is in correlates with the reduction in blow-by gases as the major contributing source ${ }^{16,17}$ as shown in Figure 10. This trend is demonstrated in Figure 12 outlining the importance of unburnt fuel flow into the ring-pack crevices upon hydrocarbon emissions.

Emissions can be reduced by optimising the fuel usage. One way of achieving this is to mitigate frictional and gas leakage losses. A breakdown for the gas flow rate emissions due to the stated losses is presented in Figure 13. Although the total emissions have decreased for an engine operating under CDA, the emissions due to friction and gas leakage have actually increased. This demonstrates the importance of taking into account the frictional losses and gas pressure leakage together for modern engines using CDA, an approach has not been reported in the open literature yet. To reduce emissions, it is important that the piston compression ring effectively seals the combustion chamber. This can reduce blow-by through the ring-pack and consequently the emissions, as well as the hydrocarbon emissions attributed to the flow of unburnt fuel mixture entering the ring-pack due to gas blow-by. ${ }^{16,17}$ However, a good ring seal can increase frictional losses. Therefore, a careful trade-off between these contradictory requirements across the engine operating conditions needs to be achieved. 


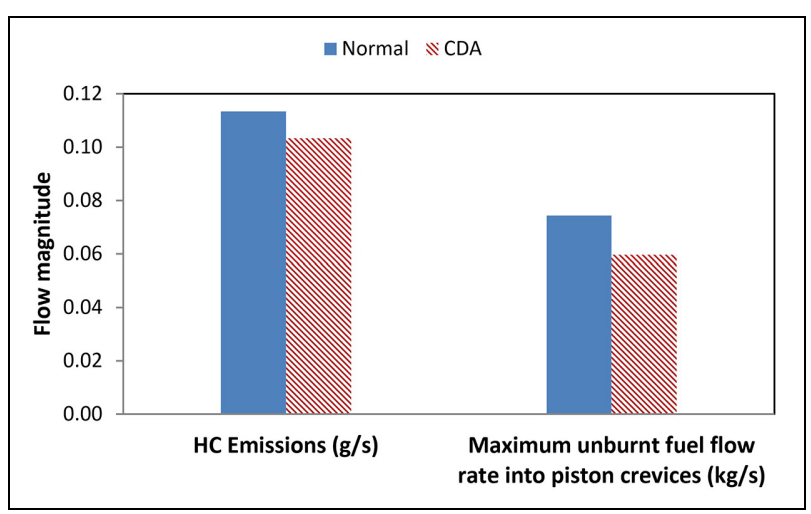

Figure 12. Trend demonstrating the reduction in predicted $\mathrm{HC}$ emissions and the maximum unburnt fuel flow into the piston ring-pack crevices.

\section{Concluding remarks}

The analysis demonstrates that the piston top compression ring of active cylinders under CDA operates in mixed regime of lubrication in the vicinity of the piston reversal for longer than when operating under normal mode of engine operation during the transition from the compression to the power stroke and much of the latter. For the case of deactivated cylinders, hydrodynamic lubrication regime seems to be more dominant apart from vicinity of piston reversals, especially at the top dead centre where the cylinder pressure is the highest. The gas flow into the crevice regions of the compression ring-to-its piston retaining lands ensures that pressure behind the inner rim of the ring builds up conforming it to the liner surface as an effective seal, but it increases contact friction. The deactivated cylinders exhibit the highest boundary friction at the TDC to the higher build-up in pressure behind the ring, demonstrating the importance of an integrated multi-physics analysis such as the one reported in this paper.

Gas pressure leakage losses are highest for an engine operating under CDA because of the high combustion pressures. The deactivated cylinders act as gas springs with higher gas pressure losses as the piston moves from BDC to TDC than from TDC to BDC. It is shown that cylinder deactivation can increase the gas leakage and frictional losses by approximately $20 \%$. This is much less than the gain in fuel savings due to reduced fuel use and pumping. However, reducing frictional and gas leakage losses is important in meeting targeted emission levels and improving fuel in modern engines especially that utilising cylinder deactivation technology.

The in-depth analysis has also shown that CDA reduces the predicted $\mathrm{CO}$ emissions by as much as $8.5 \%$, the $\mathrm{NO}_{\mathrm{x}}$ emissions by nearly $10 \%$ and $\mathrm{HC}$ emissions also by $8.7 \%$. Piston crevices are a source of $\mathrm{HC}$ emissions and an engine operating using cylinder deactivation technology reduces the amount of unburnt fuel entering the piston crevices due to gas blow-by. Therefore, the trend in reduced $\mathrm{HC}$ emissions is observed in the predicted unburnt fuel entering the

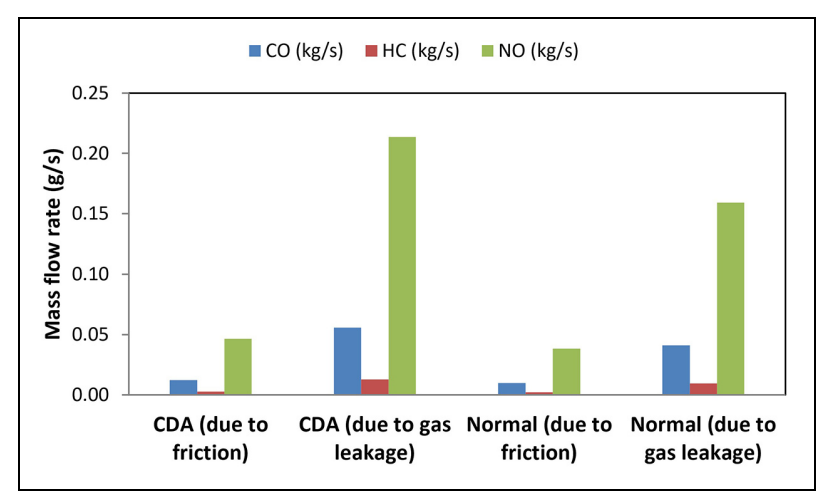

Figure 13. Breakdown of total emissions' flow rate due to friction and gas leakage.

piston crevices. Optimisation of the piston compression ring has a significant potential in reducing emissions. Objectives of reduced energy and subsequent emissions can be partially achieved through use of novel coatings on piston rings and/or cylinder liners as demonstrated in Dolatabadi et al ${ }^{67}$ and this can be considered as an extension of the current analysis using the methodology provided in the current study. Some numerical analyses have shown that use of textured features in piston ringcylinder liner contact can improving the lubrication regime, thus reducing the frictional power losses, particularly during the engine warm-up. ${ }^{68,69}$ Therefore, a holistic approach seems to be the way forward in targeting the reduction of energy losses and emissions from engine components such as the piston rings.

\section{Acknowledgement}

The authors would like to express their gratitude for the financial support of the Engineering and Physical Sciences Research Council (EPSRC) under the Encyclopaedic Program grant (EP/G012334/1) and EPSRC-funded Doctoral Centre for Training (EP/ L014998/1) in Embedded Intelligence (CDT-EI).

\section{Declaration of conflicting interests}

The author(s) declared no potential conflicts of interest with respect to the research, authorship, and/or publication of this article.

\section{Funding}

The author(s) disclosed receipt of the following financial support for the research, authorship, and/or publication of this article: This work received financial support from the Engineering and Physical Sciences Research Council (EPSRC grant numbers EP/ G012334/1 and EP/L014998/1).

\section{ORCID iDs}

Robert Turnbull (D) https://orcid.org/0000-0001-73583540 
Nader Dolatabadi (D) https://orcid.org/0000-0003-30021665

Ramin Rahmani (D) https://orcid.org/0000-0002-60848842

\section{References}

1. Pavlovic J, Marotta A and Ciuffo B. CO2 emissions and energy demands of vehicles tested under the NEDC and the new WLTP type approval test procedures. Appl Energy 2016; 177: 661-670.

2. Pavlovic J, Ciuffo B, Fontaras G, et al. How much difference in type-approval $\mathrm{CO} 2$ emissions from passenger cars in Europe can be expected from changing to the new test procedure (NEDC vs. WLTP)? Transp Res Part A Policy Pract 2018; 111: 136-147.

3. Murray $\mathbf{J}$ and King D. Climate policy: oil's tipping point has passed. Nature 2012; 481(7382): 433.

4. Aleklett K, Höök M, Jakobsson K, et al. The peak of the oil age-analyzing the world oil production reference scenario in world energy outlook 2008. Energy Policy 2010; 38(3): 1398-1414.

5. García-Olivares A, Solé J and Osychenko O. Transportation in a $100 \%$ renewable energy system. Energy Convers Manage 2018; 158: 266-285.

6. EA World energy outlook, International Energy Agency, OECD/IEA, Paris, France, 690, 2012.

7. Damiani L, Repetto M and Prato AP. Improvement of powertrain efficiency through energy breakdown analysis. Appl Energy 2014; 121: 252-263.

8. Richardson DE. Review of power cylinder friction for diesel engines. J Eng Gas Turb Power 2000; 122(4): 506-519.

9. Sandford M, Allen J and Tudor R. Reduced fel consumption and emissions through cylinder deactivation. In: Future engine and system technologies, vol. 5, London: IMechE Seminar Publications, 1998, pp.211-222.

10. Boretti A and Scalco J, Piston and valve deactivation for improved part load performances of internal combustion engines. SAE technical paper, no. 2011-01-0368, 2011.

11. Douglas KJ, Milovanovic N, Turner JWG, et al. Fuel economy improvement using combined CAI and cylinder deactivation (CDA)-an initial study. SAE technical paper, no. 2005-01-0110, 2005.

12. Oglieve CJ, Mohammadpour M and Rahnejat H. Optimisation of the vehicle transmission and the gear-shifting strategy for the minimum fuel consumption and the minimum nitrogen oxide emissions. Proc IMechE, Part D: $J$ Automobile Engineering 2017; 231(7): 883-899.

13. Morris N, Mohammadpour M, Rahmani R, et al. Optimisation of the piston compression ring for improved energy efficiency of high performance race engines. Proc IMechE, Part D: J Automobile Engineering 2017; 231(13): 1806-1817.

14. Andersson BS. Company perspectives in vehicle tribology - volvo. Tribol Ser 1991; 18: 503-506.

15. Fitzsimons B. Introduction to the importance of fuel efficiency and role of the Encyclopaedic research project. In: IMechE seminar: a drive for fuel efficiency, vol. 21. Loughborough, UK, September 2011. London: Institution of Mechanical Engineers.

16. Namazian M and Heywood JB. Flow in the piston-cylinder-ring crevices of a spark-ignition engine: effect on hydrocarbon emissions, efficiency and power. SAE technical paper, no. 820088 1982: 261-288.
17. Shayler PJ, Chick J, Darnton NJ, et al. Generic functions for fuel consumption and engine-out emissions of $\mathrm{HC}$, $\mathrm{CO}$ and $\mathrm{NO} \mathrm{x}$ of spark-ignition engines. Proc IMechE, Part D: J Automobile Engineering 1999; 213(4): 365-378.

18. Castleman RA Jr. A hydrodynamical theory of piston ring lubrication. Physics 1936; 7(9): 364-367.

19. Furuhama S. A dynamic theory of piston-ring lubrication 1st report, calculation. Bull JSME 1959; 2(7): 423-428.

20. Dowson D, Ruddy BL and Economou PN. The elastohydrodynamic lubrication of piston rings. Proc $R$ Soc $A$ 1983; 386(1791): 409-430.

21. Akalin O and Newaz GM. Piston ring-cylinder bore friction modelling in mixed lubrication regime: part I-analytical results. J Tribol 2001; 123(1): 211-218.

22. Akalin $\mathrm{O}$ and Newaz GM. Piston ring-cylinder bore friction modelling in mixed lubrication regime: part II-Correlation with bench test data. J Tribol 2001; 123(1): 219223.

23. Jeng YR. Theoretical analysis of piston-ring lubrication Part I-fully flooded lubrication. Tribol Trans 1992; 35(4): 696-706.

24. Jeng YR. Theoretical analysis of piston-ring lubrication Part II-Starved lubrication and its application to a complete ring pack. Tribol Trans 1992; 35(4): 707-714.

25. Furuhama $\mathrm{S}$ and Sasaki $\mathrm{S}$. New device for the measurement of piston frictional forces in small engines. SAE technical paper, no. 831284, 1983: 781-792.

26. Ma MT, Sherrington I and Smith EH. Analysis of lubrication and friction for a complete piston-ring pack with an improved oil availability model: part 1 : circumferentially uniform film. Proc IMechE, Part J: J. Engineering Tribology 1997; 211(1): 1-15.

27. Mishra PC, Balakrishnan S and Rahnejat H. Tribology of compression ring-to-cylinder contact at reversal. Proc IMechE, Part J: J Engineering Tribology 2008; 222(7): 815-826.

28. Mishra PC, Rahnejat $\mathrm{H}$ and King PD. Tribology of the ring-bore conjunction subject to a mixed regime of lubrication. Proc IMechE, Part C: J Mechanical Engineering Science 2009; 223(4): 987-998.

29. Fang C, Meng X, Kong X, et al. Transient tribodynamics analysis and friction loss evaluation of piston during cold- and warm-start of a SI engine. Int J Mecha Sci 2017; 133: 767-787.

30. Rahmani R, Theodossiades S, Rahnejat H, et al. Transient elastohydrodynamic lubrication of rough new or worn piston compression ring conjunction with an outof-round cylinder bore. Proc IMechE, Part J: J. Engineering Tribology 2012; 226(4): 284-305.

31. Piao Y and Gulwadi SD. Numerical investigation of the effects of axial cylinder bore profiles on piston ring radial dynamics. J Eng Gas Turb Power 2003; 125(4): 10811089.

32. Tian T. Dynamic behaviours of piston rings and their practical impact. Part 1: ring flutter and ring collapse and their effects on gas flow and oil transport. Proc IMechE, Part J: J. Engineering Tribology 2002; 216(4): 209-228.

33. Tian T. Dynamic behaviours of piston rings and their practical impact. Part 2: oil transport, friction and wear of ring/liner interface and the effects of piston and ring dynamics. Proc IMechE, Part J: J Engineering Tribology 2002; 216(4): 229-248.

34. Baker CE, Theodossiades S, Rahnejat H, et al. Influence of in-plane dynamics of thin compression rings on friction 
in internal combustion engines. J Eng Gas Turb Power 2012; 134(9): 092801.

35. Baker C, Rahmani R, Theodossiades S, et al. On the effect of transient in-plane dynamics of the compression ring upon its tribological performance. J Eng Gas Turb Power 2015; 137(3): 032512.

36. Liu Y and Tian T. Development and application of ringpack model integrating global and local processes. Part 1: gas pressure and dynamic behavior of piston ring pack. SAE Int J Engines 2017; 10(4): 1927-1939.

37. Baker C, Theodossiades S, Rahmani R, et al. On the transient three-dimensional tribodynamics of internal combustion engine top compression ring. J Eng Gas Turb Power 2017; 139(6): 062801.

38. Turnbull R, Rahmani $\mathrm{R}$ and Rahnejat H. In-plane and out-of-plane elastodynamics of thin rings and seals. $J$ Comput Nonlinear Dyn 2019; 14(8): 081006.

39. Turnbull R, Dolatabadi N, Rahmani R, et al, An assessment of gas power leakage and frictional losses from the top compression ring of internal combustion engines. Tribol Int 2019; 142: 105991.

40. Morris N, Rahmani R, Rahnejat $\mathrm{H}$, et al. Tribology of piston compression ring conjunction under transient thermal mixed regime of lubrication. Tribol Int 2013; 59: 248-258.

41. Wang X and Stone CR. A study of combustion, instantaneous heat transfer, and emissions in a spark ignition engine during warm-up. Proc IMechE, Part D: J Automobile Engineering 2008; 222(4): 607-618.

42. Mirhashemi FS and Sadrnia H. NOx emissions of compression ignition engines fueled with various biodiesel blends: a review. $J$ Energy Inst 2020; 93: 129-151.

43. Rahmani R, Rahnejat H, Fitzsimons B, et al. The effect of cylinder liner operating temperature on frictional loss and engine emissions in piston ring conjunction. Appl Energy 2017; 191: 568-581.

44. Kaiser EW, Adamczyk AA and Lavoie GA. The effect of oil layers on the hydrocarbon emissions generated during closed vessel combustion. Int Symp Combust 1981; 18(1): 1881-1890.

45. Wang Y, Liang X, Shu G, et al. Effect of lubricating oil additive package on the characterization of diesel particles. Appl Energy 2014; 136: 682-691.

46. Di Battista D and Cipollone R. Experimental and numerical assessment of methods to reduce warm up time of engine lubricant oil. Appl Energy 2016; 162: 570-580.

47. Morris N, Mohammadpour M, Rahmani R, et al. Effect of cylinder deactivation on tribological performance of piston compression ring and connecting rod bearing. Tribol Int 2018; 120: 243-254.

48. Lang TE. Vibration of thin circular rings, Part 1", jet propulsion laboratory, California Institute of Technology, Pasadena, CA, Technical Report, 1962: 32-261.

49. Rahnejat H. Multi-body dynamics: vehicles, machines, and mechanisms. Bury St Edmunds, UK: Professional Engineering Publishing, 1998.

50. Dowson D and Higginson GR. A numerical solution to the elasto-hydrodynamic problem. J Mech Eng Sci 1959; 1(1): 6-15.

51. Yang P, Cui J, Jin ZM, et al. Transient elastohydrodynamic analysis of elliptical contacts. Part 2: thermal and Newtonian lubricant solution. Proc IMechE, Part J: J Engineering Tribology 2005; 219(3): 187-200.
52. Roelands CJ. Correlational aspects of the viscosity-temperature-pressure relationship of lubricating oils. Doctoral Thesis, Technische Hogeschool te Delft, 1966.

53. Houpert L. New results of traction force calculations in elastohydrodynamic contacts. $J$ Tribol 1985; 107(2): 241-245.

54. Greenwood JA and Tripp JH. The contact of two nominally flat rough surfaces. Proc IMechE J Mechanical Engineering Science 1970; 185(1): 625-633.

55. Teodorescu $\mathrm{M}$, Balakrishnan $\mathrm{S}$ and Rahnejat $\mathrm{H}$. Integrated tribological analysis within a multi-physics approach to system dynamics. Tribol Interface Eng Ser 2005; 48: 725-737.

56. Styles G, Rahmani R, Rahnejat H, et al. In-cycle and lifetime friction transience in piston ring-liner conjunction under mixed regime of lubrication. Int J Engine Res 2014; 15(7): 862-876.

57. Eyring H. Viscosity, plasticity, and diffusion as examples of absolute reaction rates. J Chem Phys 1936; 4(4): 283291.

58. Ma Z, Henein NA and Bryzik W. A model for wear and friction in cylinder liners and piston rings. Tribol Trans 2006; 49(3); 315-327.

59. Baker CE, Rahmani R, Karagiannis I, et al. Effect of compression ring elastodynamics behaviour upon blowby and power loss. SAE technical paper, no. 2014-01-1669, 2014.

60. Theaker M, Rahmani R and Rahnejat H. Prediction of ring-bore conformance and contact condition and experimental validation. In: ASME 2012 internal combustion engine division spring technical conference, Torino, Piemonte, Ital, 6-9 May 2012, pp.885-892.

61. Heywood JB. Internal combustion engine fundamentals. New York: McGraw-Hill, 1988.

62. Woods WA. On the role of the harmonic mean isentropic exponent in the analysis of the closed-cycle gas turbine. Proc IMechE, Part A: J Power and Energy 1991; 205(4): 287-291.

63. Leonhardt S, Muller $\mathrm{N}$ and Isermann R. Methods for engine supervision and control based on cylinder pressure information. IEEE/ASME Trans Mechatron 1999; 4(3): 235-245.

64. Hohenberg $G$ and Killmann I. Basic findings obtained from measurement of the combustion process. SAE technical paper, no. 82126,1982

65. Wilkins AJJ and Hannington NA. The effect of fuel and oil additives on automobile catalyst performance. Platin Met Rev 1990; 34(1): 16-24.

66. Ljubas D, Krpan $\mathrm{H}$ and Matanović I. Influence of engine oils dilution by fuels on their viscosity, flash point and fire point. Nafta 2010; 61(2): 73-79.

67. Dolatabadi N, Forder M, Morris N, et al. Influence of advanced cylinder coatings on vehicular fuel economy and emissions in piston compression ring conjunction. Appl Energy 2020; 259: 114129.

68. Morris N, Rahmani R, Rahnejat $\mathrm{H}$, et al. A numerical model to study the role of surface textures at top dead center reversal in the piston ring to cylinder liner contact. J Tribol 2016; 138(2): 021703.

69. Morris NJ, Rahmani R and Rahnejat H. A hydrodynamic flow analysis for optimal positioning of surface textures. Proce IMechE, Part J: J Engineering Tribology 2017; 231(9): 1140-1150. 


\section{Appendix}

\section{Notation}

\begin{tabular}{|c|c|c|}
\hline A & Area of contact & $\mathrm{m}^{2}$ \\
\hline$A_{1}$ & $\begin{array}{l}\text { Control volume area normal to the } \\
\text { gas flow }\end{array}$ & $\mathrm{m}^{2}$ \\
\hline$A_{2}$ & Ring cross-sectional area & $\mathrm{m}^{2}$ \\
\hline$A_{\mathrm{e}}$ & Asperity contact area & $\mathrm{m}^{2}$ \\
\hline$B$ & Cylinder bore & $\mathrm{m}$ \\
\hline$E^{\prime}$ & $\begin{array}{l}\text { Reduced (effective) Young's elastic } \\
\text { modulus }\end{array}$ & $\mathrm{N} / \mathrm{m}^{2}$ \\
\hline$E_{1}$ & $\begin{array}{l}\text { Liner material Young's elastic } \\
\text { modulus }\end{array}$ & $\mathrm{N} / \mathrm{m}^{2}$ \\
\hline$E_{2}$ & $\begin{array}{l}\text { Ring material Young's elastic } \\
\text { modulus }\end{array}$ & $\mathrm{N} / \mathrm{m}^{2}$ \\
\hline$f_{R}$ & Radial ring force per unit length & $\mathrm{N} / \mathrm{m}$ \\
\hline$f_{0}$ & Tangential ring force per unit length & $\mathrm{N} / \mathrm{m}$ \\
\hline G & Ring modulus of rigidity & $\mathrm{N} / \mathrm{m}^{2}$ \\
\hline$h$ & Film thickness & $\mathrm{m}$ \\
\hline$h_{s}$ & $\begin{array}{l}\text { Axial profile of the ring contacting } \\
\text { face }\end{array}$ & $\mathrm{m}$ \\
\hline$h_{1}$ & Channel width & $\mathrm{m}$ \\
\hline$I_{2}$ & Second moment of area & $m^{4}$ \\
\hline $\mathbf{K}$ & Ring stiffness matrix & $\mathrm{N} / \mathrm{m}$ \\
\hline I & Length of connecting rod & $\mathrm{m}$ \\
\hline$l_{1}$ & Crevice length & $\mathrm{m}$ \\
\hline$L_{b}$ & $\begin{array}{l}\text { Crevice length exposed to burnt } \\
\text { gas }\end{array}$ & $\mathrm{m}$ \\
\hline$L_{t}$ & Total crevice length & $\mathrm{m}$ \\
\hline$L_{u}$ & $\begin{array}{l}\text { Crevice length exposed to unburnt } \\
\text { gas }\end{array}$ & $\mathrm{m}$ \\
\hline$\dot{m}_{u}$ & Mass flow rate of unburnt gas & $\mathrm{kg} / \mathrm{s}$ \\
\hline$\dot{m}_{b}$ & Mass flow rate of burnt gas & $\mathrm{kg} / \mathrm{s}$ \\
\hline M & Ring mass matrix & $\mathrm{kg}$ \\
\hline$p$ & Pressure distribution & $\mathrm{Pa}$ \\
\hline$P_{a t m}$ & Ambient (atmospheric) pressure & $\mathrm{Pa}$ \\
\hline$p_{c y l, \text { fired }}$ & Fired cylinder pressure & $\mathrm{Pa}$ \\
\hline Pcyl, motored & Motored cylinder pressure & $\mathrm{Pa}$ \\
\hline & Pressure downstream & $\mathrm{Pa}$ \\
\hline$P_{U}$ & Pressure upstream & $\mathrm{Pa}$ \\
\hline$R$ & Gas constant & $\mathrm{Jkg}^{-1} \mathrm{~K}^{-1}$ \\
\hline$R_{2}$ & Compression ring radius & $\mathrm{m}$ \\
\hline$r$ & Crank-pin radius & $\mathrm{m}$ \\
\hline$T$ & Temperature at piston top land & $\mathrm{K}$ \\
\hline$T_{U}$ & Temperature upstream & K \\
\hline$T_{0}$ & Reference temperature of the gas & K \\
\hline$t$ & Time & s \\
\hline$U$ & The axial velocity of piston & $\mathrm{m} / \mathrm{s}$ \\
\hline u & Radial ring deflection & $\mathrm{m}$ \\
\hline$V_{t}$ & Total cylinder volume & $\mathrm{m}^{3}$ \\
\hline$V_{u}$ & Volume of unburnt gas & $\mathrm{m}^{3}$ \\
\hline $\mathrm{W}_{a}$ & Load share of asperities & $\mathrm{N}$ \\
\hline$W_{h}$ & Load share of the lubricant film & $\mathrm{N}$ \\
\hline w & Circumferential ring deflection & $\mathrm{m}$ \\
\hline
\end{tabular}

\section{Greek symbols}

\begin{tabular}{|c|c|c|}
\hline$\alpha_{0}$ & Lubricant Piezo-viscosity coefficient & $\mathrm{m}^{2} / \mathrm{N}$ \\
\hline$\beta_{0}$ & $\begin{array}{l}\text { Lubricant Thermo-viscosity } \\
\text { coefficient }\end{array}$ & - \\
\hline$\gamma$ & $\begin{array}{l}\text { Coefficient of thermal expansion } \\
\text { for oil }\end{array}$ & $\mathrm{K}^{-1}$ \\
\hline$\gamma_{s}$ & Specific heat ratio & - \\
\hline$\delta$ & Localised elastic Hertzian defection & $M$ \\
\hline$\Delta$ & $\begin{array}{l}\text { Ring circumferential elastic } \\
\text { deflection }\end{array}$ & $M$ \\
\hline$\Delta \theta$ & $\begin{array}{l}\text { Circumferential discretisation } \\
\text { interval }\end{array}$ & $\mathrm{rad}$ \\
\hline$\zeta$ & $\begin{array}{l}\text { Coefficient of boundary shear } \\
\text { strength }\end{array}$ & - \\
\hline$\eta$ & Dynamic viscosity of the lubricant & Pa.s \\
\hline$\eta_{0}$ & $\begin{array}{l}\text { Dynamic viscosity of the gas at a } \\
\text { reference temperature }\end{array}$ & Pa.s \\
\hline$\theta$ & Peripheral position & $\mathrm{rad}$ \\
\hline$\kappa$ & $\begin{array}{l}\text { Average asperity tip radius of } \\
\text { curvature }\end{array}$ & $M$ \\
\hline$\lambda$ & Stribeck's oil film ratio & - \\
\hline$v_{1}$ & Liner Poisson’s ratio & - \\
\hline$v_{2}$ & Ring Poisson's ratio & - \\
\hline$\xi$ & $\begin{array}{l}\text { Asperity density per unit contact } \\
\text { area }\end{array}$ & $\mathrm{I} / \mathrm{m}^{2}$ \\
\hline$\rho$ & Lubricant density & $\mathrm{kg} / \mathrm{m}^{3}$ \\
\hline$\rho_{0}$ & Oil density at ambient pressure & $\mathrm{kg} / \mathrm{m}^{3}$ \\
\hline$\rho_{2}$ & Ring density & $\mathrm{kg} / \mathrm{m}^{3}$ \\
\hline$\sigma$ & $\begin{array}{l}\text { Composite roughness of the } \\
\text { contacting surfaces }\end{array}$ & M \\
\hline$\tau$ & Viscous shear stress & $\mathrm{N} / \mathrm{m}^{2}$ \\
\hline$\tau_{0}$ & Eyring shear stress & $\mathrm{N} / \mathrm{m}^{2}$ \\
\hline$\phi$ & Equivalence ratio & - \\
\hline
\end{tabular}

\section{Abbreviations}

\begin{tabular}{ll}
\hline ID/2D & One/Two-dimensional \\
AFM & Atomic force microscope \\
AFR & Air fuel ratio \\
BDC & Bottom dead centre \\
CDA & Cylinder de-activation \\
CFD & Computational fluid dynamics \\
FDM & Finite difference method \\
FMEP & Friction mean effective pressure \\
GFR & Gas fuel ratio \\
HC & Hydrocarbon \\
ICE & Internal combustion engine \\
LFM & Lateral force microscopy \\
MBTD & The minimum spark advance for the best \\
MFB & torque delivery \\
NOx & Mass fraction burnt \\
TDC & Nitrogen oxides \\
\hline
\end{tabular}

